\title{
Benefits of once-daily therapies in the treatment of hypertension
}

\author{
This article was published in the following Dove Press journal: \\ Vascular Health and Risk Management \\ 20 December 20II \\ Number of times this article has been viewed
}

\author{
John M Flack \\ Samar A Nasser \\ Department of Internal Medicine, \\ Divisions of Translational Research \\ and Clinical Epidemiology and \\ Endocrinology, Wayne State University \\ School of Medicine, Detroit, MI, USA
}

Correspondence: John Flack

420 I St. Antoine, 2E UHC, Detroit, MI

4820I, USA

Tel +I 3/37458244

Fax + I 3139930645

Email jflack@med.wayne.edu
Abstract: In patients with hypertension, 24-hour blood pressure control is the major therapeutic goal. The number of daily doses is one characteristic of an antihypertensive agent that may affect the adequacy of 24-hour control. One measure of therapeutic coverage is the 24-hour trough-to-peak ratio, which determines the suitability of an agent for once-daily administration. The closer an agent is to a $100 \%$ trough-to-peak ratio, the more uniform the 24 -hour coverage and therefore blood pressure control. High trough-to-peak ratio, long-acting antihypertensive medications lower blood pressure more gradually, which reduces the likelihood of adverse events attributable to abrupt drug action that occurs with shorter-acting agents. In hypertension, the natural diurnal variation of blood pressure may be altered, including elevated nighttime pressures. An optimal once-daily hypertension therapy would not only lower blood pressure but also normalize any blunted circadian variations in blood pressure. The benefits of once-daily agents with sustained therapeutic coverage may also be explained, in part, by increased patient adherence to simpler regimens as well as lower loss of blood pressure control during virtually inevitable intermittent noncompliance. Studies have demonstrated that once-daily antihypertensive agents have the highest adherence compared with twice-daily or multiple daily doses, including greater adherence to the prescribed timing of doses.

Keywords: adherence, blood pressure control, therapeutic coverage

\section{Introduction}

Current guidelines recommend antihypertensive therapies by class, taking into consideration the overall efficacy and safety profiles of the agents in each class. ${ }^{1,2}$ However, individual agents or subgroups of agents may need to be considered separately in classes that are very heterogeneous, such as diuretics, calcium channel blockers, and $\beta$-adrenergic blockers. One important drug characteristic is the duration of therapeutic coverage, which influences the required number of daily doses as well as the adequacy of blood pressure (BP) control, especially at the end of the once-daily dosing intervals (just before the next scheduled dose).

Therapeutic coverage of an antihypertensive agent equates to the amount of time $\mathrm{BP}$ is under control with a single dose. ${ }^{3}$ When an agent has a short therapeutic effect, multiple daily doses are necessary. ${ }^{3}$ The number of daily doses in an antihypertensive regimen affects BP control by different means. A mistimed or missed dose, for example, may have clinically relevant consequences on BP control if the time between doses exceeds the period of therapeutic coverage. ${ }^{4}$ Moreover, adherence and compliance appear to be reduced with complex, multiple-dose regimens. ${ }^{5}$ Therefore, a once-daily antihypertensive agent that provides genuine 24-hour BP control may 
increase adherence, resulting in improved efficacy and long-term clinical outcomes.

Another important factor is how well the therapeutic coverage of different agents works in combination. Class combinations are useful in achieving BP goals, as the majority of patients will need two or more agents. ${ }^{1,2}$ In fact, guidelines recommend initiating antihypertensive treatment with two agents if patients are $20 / 10 \mathrm{~mm} \mathrm{Hg}$ or 15/10 mm Hg above their identified BP goal. ${ }^{1,2}$ However, therapeutic gaps in coverage resulting in uneven 24-hour BP control may occur from using multiple antihypertensives with different lengths of therapeutic coverage, especially when adherence is irregular between individual agents.

This review will evaluate the available clinical evidence for 24-hour BP control with once-daily or multiple-daily dosing regimens. The effects of increasing the number of daily doses on adherence and BP control as well as reported intermediate clinical outcomes or BP effects of mistimed or missed doses will be evaluated.

\section{Effect of increasing the number of daily antihypertensive doses on 24-hour BP control}

In clinical studies, therapeutic coverage is reported as a percentage of the 24-hour period or as a placebo-corrected trough-to-peak ratio, ${ }^{3,6,7}$ and even when trough-to-peak ratios exceed $50 \%$, the higher the better. The mean decrease in BP 24 hours after the antihypertensive dose is termed the trough, and the peak represents when the mean BP decrease is maximal after receiving the antihypertensive agent. ${ }^{4}$ Therefore, the BP decrease at the trough is compared with the BP decrease at the peak. Values obtained with the antihypertensive agent should be subtracted from placebo values when calculating the trough-to-peak ratio. The trough-to-peak ratio provides a duration of action index for each antihypertensive agent and identifies drug regimens that would provide adequate BP reductions at the end of the dose interval without risk of excessively lowering BP at its peak effect and result in adverse events such as hypotension. ${ }^{4,8}$ The United States Food and Drug Administration (FDA) recommended in 1990 that the mean antihypertensive effect of an agent at trough compared with the effect at the agent's therapeutic peak was to be at least $50 \%{ }^{4,8,9}$ If an agent studied with oncedaily dosing produces a placebo-adjusted trough-to-peak ratio that exceeds $50 \%$, then it may be administered once daily. ${ }^{10}$ Antihypertensive agents with lower trough-to-peak ratios require multiple daily doses to achieve an acceptable trough-to-peak ratio. ${ }^{3}$ An agent that has an acceptable trough-to-peak ratio for once-daily administration will have more uniform BP control throughout the day compared with an agent that has an unacceptable trough-to-peak ratio (Figure 1). ${ }^{11}$

A higher trough-to-peak ratio indicates a longer duration of action and may provide a better risk-to-benefit ratio through optimal therapeutic coverage during the nighttime and early morning hours with fewer adverse events. ${ }^{3,12}$ BP control should be maintained in the early morning hours in patients with BP rise because the rate of cardiovascular events peaks in the morning hours between $6 \mathrm{AM}$ and 12 $\mathrm{PM}$, and the two events are thought to be associated. ${ }^{3,13} \mathrm{In}$ a recent 5-year study involving 10 normotensive elderly volunteers and 32 elderly patients with well-controlled hypertension, a morning surge in systolic BP (SBP) of $34 \mathrm{~mm} \mathrm{Hg}$ or more was, independent of both clinic and ambulatory BP (ABP), associated with an increased risk of cardiovascular events compared with a morning surge in SBP of less than $34 \mathrm{~mm} \mathrm{Hg} .{ }^{14}$ Therefore, antihypertensive medications that reduce the extent of the early morning BP rise may reduce the vascular risk in patients with hypertension. One analysis illustrates the difference a longer duration of action can have on early morning BP rise. A comparison of the effect of telmisartan $80 \mathrm{mg}$ once daily (trough-topeak ratio of approximately $90 \%$ ) versus ramipril $10 \mathrm{mg}$ once daily (trough-to-peak ratio of approximately 50\%) on early morning BP rise from the pooled data of two studies in patients with hypertension showed that telmisartan was associated with a $1.8-\mathrm{mm} \mathrm{Hg}$ lesser rise from nadir in SBP compared with ramipril. ${ }^{15}$ Moreover, telmisartan provided lower BP values throughout the 24-hour dosing period compared with ramipril in the two studies..$^{16,17}$ The timing of the administration of an antihypertensive agent can affect the early morning surge in BP. In 238 patients with untreated

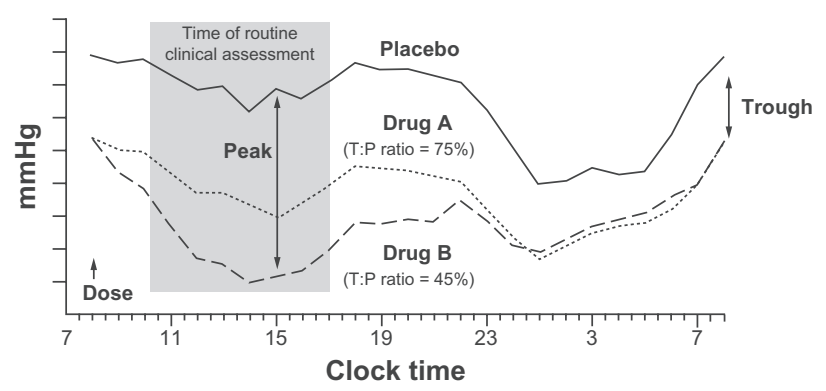

Figure I Blood pressure responses during a steady-state 24-hour dose interval for an agent with an acceptable (75\%) trough-to-peak ratio (A) and an agent with an unacceptable (45\%) trough-to-peak ratio (B).

Note: Adapted with permission from Meredith."

Abbreviations: $P$, peak; $T$, trough. 
hypertension, 8 weeks of bedtime nifedipine gastrointestinal therapeutic system (GITS) dosing reduced the morning rise in SBP and diastolic BP (DBP) from the nocturnal nadir by -6.2 and $-4.4 \mathrm{~mm} \mathrm{Hg}$, respectively $(P<0.001)$, while the morning nifedipine GITS dose had no such effect. ${ }^{18}$ In addition, overall ABP control was higher (43\% versus $28 \%, P=0.019)$ with nighttime dosing versus morning dosing, ${ }^{18}$ however, the effects of nighttime dosing on the trough-to-peak ratio have not been examined.

Patients with hypertension also have larger fluctuations in their BP levels throughout the day compared with normotensive individuals. ${ }^{19}$ Shorter-acting agents may allow for greater daytime variations in BP, making the 24-hour trough-to-peak ratio difficult to interpret. This was reported in a study involving 30 patients treated with felodipine $10 \mathrm{mg}$ once daily or nifedipine $20 \mathrm{mg}$ twice daily for 2 weeks. ${ }^{20}$ The placebo-corrected SBP/DBP trough-to-peak ratio was $80 \% / 75 \%$ for felodipine. However, nifedipine produced a biphasic change in 24-hour BP readings, and the trough-to-peak ratio was not calculated. Although both agents produced similar decreases in BP values, there were fewer variations in daytime BP as assessed by 24-hour ABP monitoring with longer-acting felodipine. Moreover, an analysis of data from the Anglo-Scandinavian Cardiac Outcomes Trial Blood Pressure Lowering Arm (ASCOT-BPLA) trial demonstrated that BP variability decreased over time with amlodipine-based treatment (5-10 mg; 50\%-100\% trough-to-peak ratio ${ }^{21}$ ) but increased with atenolol-based treatment (50-100 mg; 46\% troughto-peak ratio $\left.{ }^{22}\right){ }^{23-25}$ Large fluctuations in BP throughout the day, which may occur with a lower trough-to-peak ratio, may therefore be ameliorated with a high trough-to-peak ratio once-daily agent. ${ }^{3}$

In another study by Goyal and colleagues, 29 patients were recruited based on the original criteria for the Heart Outcomes Prevention Evaluation (HOPE) study and were given ramipril either in twice-daily dose ( $5 \mathrm{mg}$ bid) or once-daily (10 mg q AM) each morning in a randomized, prospective cross-over trial. ${ }^{26}$ Twenty-four hour ABP recordings were taken prior to initiation of ramipril therapy and after treatment with twice-daily and once-daily ramipril. The results showed that ramipril caused a significant reduction of BP over a 24-hour period as compared with baseline. The mean baseline ABP of $124 / 73 \mathrm{~mm} \mathrm{Hg}$ fell to $117 / 69 \mathrm{~mm} \mathrm{Hg}$ on the twice-a-day regimen $(P<0.001)$ and to $115 / 68 \mathrm{~mm}$ $\mathrm{Hg}$ for the daily morning regimen $(P<0.001)$. There was a trend to better 24-hour BP control with once-daily dosing as compared with twice-daily dose of ramipril, but the difference was not statistically different. Though not conclusive, these data suggested slightly better early morning (5 am-8 am) BP control with twice-daily than the usual once-daily morning dosing.

Nighttime BP normally decreases 10\%-20\% from daytime values. ${ }^{27}$ However, up to $50 \%$ of patients with hypertension may not exhibit this normal reduction in BP. ${ }^{28,29}$ In one study of 8384 untreated patients with hypertension, $35 \%$ of the patients were nondippers, $8.8 \%$ were classified as extreme dippers (nocturnal BP decline $>20 \%$ ), and $6 \%$ were classified as risers. ${ }^{29}$ If the BP percentage change at night is on either side of the range considered normal, then a patient is considered to have an abnormal diurnal variation. ${ }^{28}$ Evidence from clinical trials has shown that the once-daily antihypertensive agents verapamil and amlodipine reduce nighttime BP in patients who lack a nocturnal BP decrease without excessive lowering of nighttime BP in those patients with normal or excessive pretreatment nocturnal declines in BP. ${ }^{30,31}$ Alternatively, evening dosing also provides effective 24-hour BP control while preferentially increasing the decline in nocturnal BP in patients with a nondipper status. For example, in 90 patients randomized to receive morning or evening valsartan (160 mg/day), ABP monitoring demonstrated similar mean BP reductions between the two treatment groups. ${ }^{32}$ However, the evening valsartan dose preferentially lowered nocturnal BP compared with the morning dose, which translated into a $73 \%$ relative reduction in the proportion of patients with nondipper status. In the HOPE study, evaluating nighttime ramipril (10 mg/day) for 5 years in patients $(\mathrm{N}=9297)$ with hypertension and at high risk for cardiovascular events, ABP monitoring in 38 patients with peripheral arterial disease demonstrated a significant improvement in the diurnal-nocturnal ratio at 1 year $(P<0.01) .{ }^{33,34}$ These results suggest that the clinical benefits observed in the overall HOPE study may be related to the ABP reduction, especially at nighttime. Moreover, ramipril reportedly has a relatively smooth effect on 24-hour BP among angiotensin-converting enzyme inhibitors. ${ }^{33}$ Therefore, an agent with a high smoothness index may not translate to an effective improvement in the diurnal-nocturnal ratio. However, a limitation of the HOPE study is the lack of a morning comparison group. The Monitorizacion Ambulatoria de Presion arterial y Eventos Cardiovasculares (MAPEC) study reported great BP control rates in patients $(\mathrm{N}=2156)$ with hypertension receiving more than one antihypertensive at nighttime versus taking all antihypertensive medication upon arising after a mean follow-up of 5.6 years. ${ }^{35}$ 


\section{Variations in 24-hour coverage among once-daily antihypertensive agents}

The therapeutic coverage of once-daily dosing varies among antihypertensive agents such that the therapeutic effect may be either less than or longer than 24 hours. In fact, the trough-to-peak ratios of individual agents differ as much within an antihypertensive drug class as between classes. ${ }^{8}$ The importance of these therapeutic differences becomes apparent with mistimed doses. It should be noted that the trough-to-peak ratio can be used to evaluate any dosing regimen frequency (eg, for a drug that is administered 2 or 3 times daily, as long as the calculated trough-to-peak ratio is greater than $50 \%$ when the drug is dosed at that frequency, the dosing regimen would be considered appropriate).

Among the angiotensin receptor blockers, the trough-to-peak ratios for once-daily monotherapy were reported for four agents in clinical trials and were all higher than $50 \%{ }^{36-39}$ The trough-to-peak ratio with candesartan cilexetil was shown to range from $80 \%$ to $100 \%$, whereas the trough-to-peak ratio with valsartan was $66 \%{ }^{37,38}$ The trough-to-peak ratio in patients with hypertension was $70 \%$ for once-daily losartan $50 \mathrm{mg}$ compared with $90 \%-110 \%$ for once-daily candesartan 8 or $16 \mathrm{mg}$ after 8 weeks of treatment. ${ }^{39} \mathrm{In} 207$ patients treated with once-daily telmisartan 40,80 , or $120 \mathrm{mg}$ or enalapril $20 \mathrm{mg}$ once daily for 28 days, the DBP trough-to-peak ratios were $85 \%$ or higher for all telmisartan doses and $65 \%$ for enalapril. ${ }^{40}$ These studies also showed a positive relationship of the dose to the trough-to-peak ratio.

A review of clinical trials using once-daily angiotensinconverting enzyme inhibitors ( 24 trials) and calcium channel blockers (34 trials) calculated the trough-to-peak ratios among individual agents in these two classes (Table 1). ${ }^{21,41-46}$ Among both classes of agents, trough-to-peak ratios ranged, in general, from $10 \%$ to $80 \%$, with five agents reporting up to $100 \%$ (perindopril, trandolapril, amlodipine, lacidipine, and verapamil).

Only one study has reported the therapeutic coverage of the direct renin inhibitor aliskiren. An 8-week study in 355 elderly patients with hypertension reported that the SBP trough-to-peak ratios of aliskiren $75 \mathrm{mg}, 150 \mathrm{mg}$, and $300 \mathrm{mg}$ were $77 \%, 64 \%$, and $79 \%$, respectively. ${ }^{47}$

The majority of clinical trials conducted with diuretics did not include trough-to-peak ratio information. However, one study of pooled data involving 216 patients with hypertension provided trough-to-peak ratio information for both indapamide sustained release (SR) $1.5 \mathrm{mg}$ once daily and immediate release (IR) $2.5 \mathrm{mg}$ once daily. ${ }^{48,49}$
Table I Diastolic trough-to-peak ratios of angiotensin-converting enzyme inhibitors and calcium channel blockers as administered once daily

\begin{tabular}{|c|c|c|c|}
\hline \multirow[t]{2}{*}{ Agent (dose) } & \multicolumn{3}{|c|}{ Average trough-to-peak ratio, $\%$} \\
\hline & $\begin{array}{l}\text { More than } \\
50 \%\end{array}$ & $50 \%$ & $\begin{array}{l}\text { Less than } \\
\mathbf{5 0 \%}\end{array}$ \\
\hline \multicolumn{4}{|c|}{ Angiotensin-converting enzyme inhibitors } \\
\hline Perindopril ${ }^{a}(2-16 \mathrm{mg})$ & $\sim 75-100$ & & \\
\hline Fosinopril (20 mg) & 64 & & \\
\hline Ramipril (5 and $10 \mathrm{mg}$ ) & $50-63$ & & \\
\hline Trandolapril (I and $2 \mathrm{mg}$ ) & $50-100$ & & \\
\hline Enalapril $(5,10$, and $20 \mathrm{mg})$ & $40-64$ & & \\
\hline Benazeprila $(20-80 \mathrm{mg})$ & & $\sim 50$ & \\
\hline Quinaprila (10-80 mg) & & $\sim 50$ & \\
\hline Lisinopril (10-80 mg) & & $30-70$ & \\
\hline Captoprilb (25-100 mg) & & & 25 \\
\hline Cilazapril (2.5 and $5.0 \mathrm{mg}$ ) & & & $10-80$ \\
\hline \multicolumn{4}{|l|}{ Calcium channel blockers } \\
\hline Amlodipine (5-10 mg) & $50-100$ & & \\
\hline Lacidipine (2-6 mg) & $40-100$ & & \\
\hline $\begin{array}{l}\text { Nifedipine Coat-Core } \\
(30 \text { and } 60 \mathrm{mg} \text { ) }\end{array}$ & $50-69$ & & \\
\hline $\begin{array}{l}\text { Nifedipine GITS } \\
(30 \text { and } 60 \mathrm{mg} \text { ) }\end{array}$ & $60-94$ & & \\
\hline $\begin{array}{l}\text { Verapamil slow-release } \\
\text { formulations }(240 \mathrm{mg})\end{array}$ & $45-100$ & & \\
\hline $\begin{array}{l}\text { Isradipine slow-release } \\
\text { formulations }^{\mathrm{a}}(5,10, \mathrm{I} \text {, } \\
\text { and } 20 \mathrm{mg})\end{array}$ & $76-100$ & & \\
\hline $\begin{array}{l}\text { Diltiazem slow-release } \\
\text { formulations }(120,240 \text {, } \\
300,360 \text {, and } 480 \mathrm{mg})\end{array}$ & & $20-80$ & \\
\hline $\begin{array}{l}\text { Felodipine } \mathrm{ER}^{\mathrm{a}}(2.5,5,10 \text {, } \\
\text { and } 20 \mathrm{mg})\end{array}$ & & & $\sim 40-50$ \\
\hline Nitrendipine (10-20 mg) & & & $10-80$ \\
\hline
\end{tabular}

After 2 months of indapamide treatment, the SBP/DBP trough-to-peak ratios were $89 \% / 85 \%$ for indapamide SR and $104 \% / 98 \%$ for indapamide IR. Importantly, this study illustrates that a higher dose of a shorter-acting agent can achieve an acceptable trough-to-peak ratio. However, this is typically not desirable because the incidence of adverse events may increase; although in this trial there was no difference in adverse events reported between the two treatments.

There are many $\beta$-adrenergic blocking agents with reported trough-to-peak ratios, the majority of which are higher than $50 \%$ (Table 2). ${ }^{10,22,50-54}$ Atenolol administered once daily had disparate values of trough-to-peak ratios reported, probably because of the doses used in each study $\left(200 \mathrm{mg} /\right.$ day [104\%] versus up to $100 \mathrm{mg} /$ day [46\%]). ${ }^{22,50,51}$ Metoprolol doses of up to $400 \mathrm{mg}$ /day also had a low 
Table 2 Trough-to-peak ratios of $\beta$-adrenergic receptor-blocking agents

\begin{tabular}{|c|c|}
\hline Agent (dose) & Trough-to-peak ratio, \% \\
\hline Acebutolol DBP (400-800 mg) & 71 \\
\hline Atenolol DBP and MAPa (50-200 mg) & 46 and $104^{a}$ \\
\hline Bisoprolol MAP (5 mg) & 58 \\
\hline Betaxolol SBP/DBP ( 10 and $20 \mathrm{mg}$ ) & $73 / 72$ \\
\hline Carvedilol I2-hour MAP (25 mg) & 85 \\
\hline \multicolumn{2}{|l|}{ Carvedilol CR DBP } \\
\hline $20 \mathrm{mg} /$ day & 73 \\
\hline $40 \mathrm{mg} /$ day & 64 \\
\hline $80 \mathrm{mg} / \mathrm{day}$ & 65 \\
\hline Metoprolol MAP (200, 300, and $400 \mathrm{mg}$ ) & $44^{\mathrm{b}}$ \\
\hline Metoprolol tartrate extended-release & $71 / 67$ \\
\hline \multicolumn{2}{|l|}{ SBP/DBP (I00 and $200 \mathrm{mg})$} \\
\hline \multicolumn{2}{|l|}{ Nebivolol } \\
\hline Overall, 5 mg & 91 \\
\hline SBP/DBP, $5 \mathrm{mg}$ & $72 / 88$ \\
\hline Pindolol MAP (15, 30, and 45 mg) & 70 \\
\hline Propranolol, slow-release formulation & 107 \\
\hline $\operatorname{MAP}(160,320,480$, and $640 \mathrm{mg})$ & \\
\hline
\end{tabular}

Notes: Data from Floras et al, ${ }^{50}$ Kuroedov et al, ${ }^{54}$ Neutel et al, ${ }^{51}$ Soucek et al, ${ }^{10}$ Stoschitzky et al, ${ }^{52}$ Weber et al, ${ }^{53}$ and Wing, ${ }^{22}$ a $104 \%$ was based on $200 \mathrm{mg}$ atenolol per day; bbased on once-daily administration.

Abbreviations: CR, controlled release; DBP, diastolic blood pressure; MAP, mean arterial pressure; SBP, systolic blood pressure.

trough-to-peak ratio reported in one study (44\%); however, this value was based on once-daily administration. ${ }^{22,50}$

A few studies reported trough-to-peak ratios when combinations of antihypertensive agents were used (Table 3). ${ }^{36,55-58}$ Valsartan plus hydrochlorothiazide reported a similar troughto-peak ratio $(61 \% / 57 \%)$ as that reported with valsartan alone in a previously described study (66\%). ${ }^{38,58}$ Therefore, the duration of action was not affected by the addition of another agent, although BP was lower with the combination treatment. Moreover, among 20 African-American patients, who are often more resistant to hypertension therapies, valsartan (with hydrochlorothiazide added to control BP) had a SBP/DBP trough-topeak ratio of $94 \% / 91 \%$ after $8-10$ weeks of treatment. ${ }^{59}$

Table 3 Trough-to-peak ratios of combination antihypertensive therapy

\begin{tabular}{ll}
\hline Combination & Trough-to-peak ratio, $\%$ \\
\hline Amiloride/HCTZ (2.5/5 mg) versus & 50 to $>70 / 50$ to $>90$ \\
Nifedipine GITS (30 mg), SBP/DBP & $>60$ to $80 />55$ to 75 \\
Irbesartan/HCTZ (300/25 mg), SBP/DBP & $92 / 84$ \\
& $97 / 89$ in responders \\
Losartan/HCTZ (I00/25 mg), SBP/DBP & $88 / 86$ \\
Losartan/Nifedipine GITS (50/20 mg), DBP & 70 \\
Valsartan/HCTZ (80/I2.5 mg) versus & $61 / 57$ (76/74 in responders) \\
Amlodipine (5, I0 mg), SBP/DBP & $56 / 56$ (66/62 in responders) \\
\hline Note: Data from Coca et al, ${ }^{36}$ Coca et al, ${ }^{55}$ Kuschnir et al, ${ }^{56}$ Mancia et al, ${ }^{57}$ and \\
Palatini et al. ${ }^{58}$ \\
Abbreviations: DBP, diastolic blood pressure; GITS, gastrointestinal therapeutic \\
system; HCTZ, hydrochlorothiazide; SBP, systolic blood pressure.
\end{tabular}

\section{Missed antihypertensive doses}

Effects on BP when an antihypertensive dose is missed or mistimed depend on the agent's total therapeutic coverage. Among the once-daily agents, therapeutic effects may not last beyond 24 hours, resulting in loss of BP control (Figure 2). ${ }^{4}$ For example, in 246 patients treated with once-daily amlodipine (5-10 mg; 50\%-100\% trough-to-peak ratio ${ }^{21}$ ) or oncedaily valsartan (40-80 mg; 66\% trough-to-peak ratio ${ }^{38}$ ) for 12 weeks, a simulated dose omission via single-blind placebo dose resulted in a 48-hour gap in dosing. ${ }^{60}$ Greater control of morning BP rise was reported in amlodipine-treated patients compared with valsartan-treated patients after 48 hours without antihypertensive medication (DBP, $P<0.04$; SBP, $P=$ not significant). ${ }^{60}$ In another trial involving 96 patients with hypertension who were treated with once-daily amlodipine 5-10 mg $\left(50 \%-100 \%\right.$ trough-to-peak ratio $\left.{ }^{21}\right)$ or once-daily perindopril 4-8 mg (35\% trough-to-peak ratio $\left.{ }^{21}\right)$ for 60 days, BP decreases were similar between the treatment groups. However, 48 hours after last doses, amlodipine SBP/DBP values were 7.3/4.8 mm $\mathrm{Hg}$ lower than in the perindopril group $(P \leq 0.05$ for SBP and DBP). ${ }^{61} \mathrm{~A}$ final study comparing once-daily candesartan 8 and $16 \mathrm{mg}\left(80 \%-100 \%\right.$ trough-to-peak ratio $\left.{ }^{37}\right)$ with oncedaily losartan 50 and $100 \mathrm{mg}$ (70\% trough-to-peak ratio $\left.{ }^{39}\right)$ for 8 weeks in 268 patients with hypertension showed that at 48 hours after the last dose, patients receiving candesartan had lower mean SBP and DBP compared with those receiving losartan $(P<0.001$ for both $){ }^{62}$

\section{Clinical implications of BP variations}

$\mathrm{BP}$ has a natural diurnal variation that may be altered in patients with hypertension. ${ }^{12}$ In addition to the differences in early morning rise and variability throughout the day

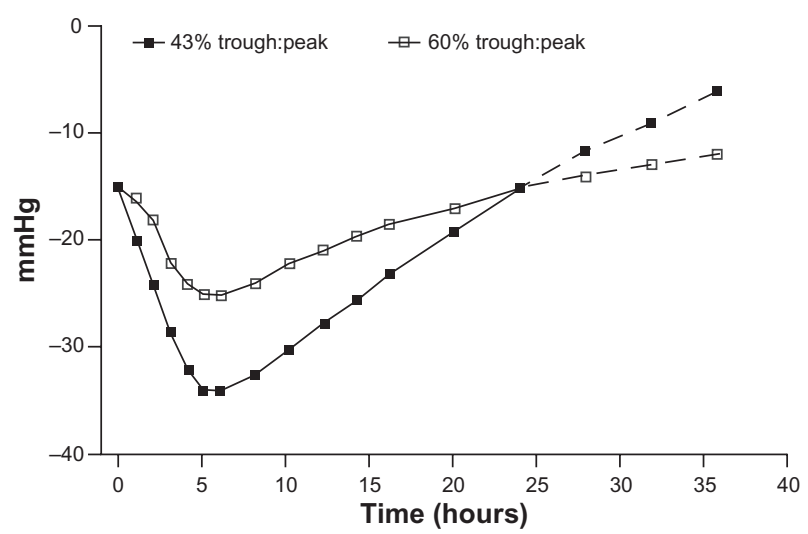

Figure 2 Placebo-corrected blood pressure responses beyond a 24-hour dosing interval for two antihypertensive agents: one with a high trough-to-peak ratio and one with a lower trough-to-peak ratio.

Note: Adapted with permission from Meredith and Elliott. ${ }^{4}$ 
mentioned previously, nighttime BP may not decrease to the same extent in patients with hypertension as in normotensive individuals. Clinical studies have reported that patients with hypertension who lack a normal nocturnal BP pattern have an elevated risk of target organ damage and cardiac events compared with hypertensive patients who have a normal nocturnal BP decrease. ${ }^{63,64}$ In fact, nighttime $\mathrm{BP}$ is a more sensitive prognostic factor for cardiovascular mortality risk than ABP monitoring, with a $21 \%$ increased risk for each 10-mm $\mathrm{Hg}$ higher nighttime SBP $(P<0.001)$ and a $9 \%$ greater risk for each 5-mm $\mathrm{Hg}$ higher nighttime DBP $(P<0.01) .{ }^{65}$ Additionally, in the MAPEC study, over median follow-up of 5.6 years, nighttime dosing of one or more antihypertensive medications compared with ingestion of all antihypertensive medications upon awakening reduced the relative risk of total cardiovascular events $(P<0.001)$ and major events (death, myocardial infarction, ischemic stroke, and hemorrhagic stroke; $P<0.001)$ compared with patients who received their medication in the morning. ${ }^{35}$ An optimal antihypertensive medication should provide uniform 24-hour BP control and also bring the diurnal variation closer to normal.

Antihypertensive medications that are dosed once daily are typically administered in the morning rather than in the evening. However, there is a body of data suggesting that antihypertensive agents representing several drug classes lower BP more effectively at night with no loss of BP control during the awake, active daytime hours; in some instances, nighttime dosing has been linked to greater overall ambulatory BP control. Quinapril, an angiotensin-converting enzyme (ACE) inhibitor dosed once daily, either in the morning or evening, lowered BP more effectively throughout the 24 hour ABP recording when dosed in the evening versus the morning. ${ }^{66}$ Accordingly, evening dosing with quinapril causes less pronounced but more sustained reductions in plasma ACE inhibition than morning dosing. ${ }^{66}$ Telmisartan, an angiotensin receptor blocker (ARB), dosed in the evening more effectively restored the normal nocturnal decline in BP with similar overall 24-hour BP lowering efficacy compared with morning dosing. ${ }^{67}$ Both doxazosin, an alpha blocker, and sustained release isradipine, a dihydropyridine calcium antagonist, when administered in the evening to patients with chronic kidney failure and hypertension, normalized nocturnal BP more effectively than morning dosing with better overall 24-hour BP control. ${ }^{68}$ These data in aggregate suggest that usual patterns of dosing once daily antihypertensive agents may not optimally lower BP and therefore provide maximum protection against cardiovascular disease (CVD).
As previously discussed, high early morning surges may increase the risk of cardiovascular events. In a study of elderly patients with hypertension, an early morning SBP surge (assessed during first 2 hours after waking versus lowest nighttime measurement) of $10 \mathrm{~mm} \mathrm{Hg}$ was associated with a $22 \%$ greater risk of stroke independent of 24-hour BP levels. ${ }^{69}$ Other prospective studies report conflicting results, with large morning surges associated with a lower overall cardiovascular risk, a higher overall cardiovascular risk, ${ }^{70}$ or a higher risk of stroke. ${ }^{71}$

Oscillations in BP throughout the day may cause, as well as be a consequence of, target organ injury. ${ }^{72} \mathrm{BP}$ variability increases as BP rises and it may play a role in cardiovascular events and the development of target organ damage. ${ }^{72}$ A multivariate analysis of data from 180 patients with suspected hypertension showed that awake SBP variability was an independent predictor of intima-media thickness $(P=0.015)$, left ventricular mass index $(P=0.028)$, and microalbuminuria $(P=0.01) .{ }^{73}$ These correlations were independent of mean BP levels. Furthermore, in 108 patients with moderate to severe hypertension, patients with a low variability in 24-hour mean BP had a lower prevalence and severity of target organ damage than those in whom the 24-hour mean BP variability was high $(P<0.05) \cdot{ }^{74}$ A multiple regression analysis of data from 73 patients with follow-up data for a mean of 7.4 years showed that long-term BP variability at the initial evaluation was significantly correlated to the magnitude of end-organ damage at follow-up $(P<0.05) .{ }^{75}$

\section{Relationship between adherence and number of daily antihypertensive doses}

Adherence and/or compliance is currently defined as the extent to which patients take their medications as prescribed. ${ }^{5,76}$ This definition may include both the correct number and the correct timing of doses each day. Adherence is usually expressed as a rate; the percentage of prescribed medication doses taken over a specified time period. ${ }^{5,76}$ Assessments of adherence rate may be direct or indirect: direct methods include observation and measurement of the agent in blood, and indirect methods include clinical response, patient self-reports, pill counts, prescription refill rate (medication possession ratio), and electronic medication monitoring. ${ }^{5}$ Each of these assessments has advantages and disadvantages regarding accuracy, cost, and convenience. However, one of the key reasons for poor BP control is lack of patient adherence, and several trials have evaluated adherence and BP control. ${ }^{77}$ One analysis involving 840 patients 
with hypertension receiving antihypertensive monotherapy demonstrated that an adherence of $80 \%$ or greater was associated with a $45 \%$ greater likelihood of achieving BP control compared with an adherence less than $80 \%{ }^{78}$ Another analysis of chronic conditions, including hypertension, has proposed a rate of $80 \%$ as the cutpoint between medication adherence and nonadherence based on the rate of hospitalizations during treatment. ${ }^{79}$ Additionally, a recent analysis of patient self-reports, prescription refill records, and electronic monitor data from two studies also concluded that $80 \%$ adherence was an appropriate cutpoint because this rate provided a balance between sensitivity and specificity for all adherence assessments. $^{80}$

\section{Increased adherence with once-daily dosing}

Several studies in patients with hypertension have demonstrated that once-daily antihypertensive medications achieve increased adherence compared with twice-daily or multiple-daily dosing. ${ }^{81-83}$ In a meta-analysis of eight hypertension studies, once-daily dosing was associated with greater adherence by $5.7 \%$ compared with twice-daily dosing $(P=0.026) .{ }^{81}$ Similar results were obtained from the comparison of once-daily dosing and multiple-daily dosing $(8.2 \%$ difference; $P<0.001)$. A meta-analysis of 76 electronic monitoring studies, including 17 hypertension studies, showed that the mean dose-taking compliance was $79 \%$ for once-daily doses, $69 \%$ for twice-daily doses, $65 \%$ for 3 daily doses, and $51 \%$ for 4 daily doses. ${ }^{82}$ Once-daily dosing was significantly associated with improved compliance compared with 3 daily doses $(P=0.008)$ and 4 daily doses $(P<0.001)$, although there was no statistical difference between once-daily and twice-daily dosing in this analysis. In another 6-month hypertension study involving 162 patients who were not included in the previous meta-analysis, oncedaily dosing was associated with slightly greater compliance compared with twice-daily dosing (98.9\% versus $97.5 \%$, respectively). ${ }^{83}$ Although patients in both regimens would be considered adherent, there were important differences in correct dosing periods favoring once-daily dosing.

Previously, evidence was shown supporting the clinical consequences of a missed dose; however, mistimed doses may also negatively affect BP control depending on the therapeutic coverage of the agent. ${ }^{3}$ Clinical studies have shown that adherence to the correct timing of doses is affected by the number of daily doses. ${ }^{82,83}$ In the previously described study involving 162 patients, correct dosing periods were achieved by $94.0 \%$ of patients in the once-daily medication group and only $78.1 \%$ of patients in the twice-daily medication group $(P=0.0001) .{ }^{83}$ Therefore, there was a lower proportion of patients in the twice-daily group who took their medications within the correct time window. The majority of patients had incorrect dosing periods attributed to delayed doses rather than to missed doses. Once-daily dosing decreased the percentage of delayed doses compared with twice-daily dosing $(1.8 \%$ versus $11.7 \%$, respectively; $P=0.0001)$, whereas the percentage of missed doses was similar $(2.6 \%$ versus $3.3 \%$, respectively; $P=0.06$ ). Once-daily dosing was also associated with increased correct dose timing compared with multiple daily doses. In the meta-analysis of 76 studies, 14 studies reported dose timing, and once-daily dosing increased the rate of dose-timing compliance compared with multiple daily dosing ( $74 \%$ versus $58 \%$ for twice daily, $46 \%$ for 3 times daily, and $40 \%$ for 4 times daily). ${ }^{82}$ Moreover, once-daily dosing can increase the percentage of days the correct number of doses is taken. Overall, once-daily antihypertensive medications improve all aspects of adherence compared with multiple daily doses, which may improve clinical outcomes.

\section{Effect of increased adherence on BP and clinical outcomes}

In hypertension, only a few studies reported on adherence and clinical outcomes. In three studies, BP control was greater in patient groups that had higher adherence. ${ }^{78,83,84}$ Additional analyses in the previously described study involving 162 patients with hypertension, wherein once-daily and twice-daily antihypertensive regimens had adherence greater than $80 \%$ but the proportion of patients with correct dosing periods was lower with the twice-daily regimen, demonstrated that BP control $(<140 / 90 \mathrm{~mm} \mathrm{Hg})$ was achieved in $41 \%$ of patients with once-daily dosing and $27 \%$ of patients with twice-daily dosing. ${ }^{83}$ In another trial involving 198 patients with mild hypertension, adherence of $80 \%$ or more augmented the reduction in BP reduction by approximately $7 \mathrm{~mm} \mathrm{Hg}$ compared with adherence of $79 \%$ or less $(P<0.05)$ after 20 weeks of treatment with the twice-daily agent. ${ }^{84}$ However, BP reductions reported with a once-daily agent were similar regardless of adherence rate, probably because delayed or missed doses with the long-acting agent had less effect on the office BP assessment. A retrospective claims database review of 840 patients with hypertension receiving monotherapy showed that $43 \%$ of patients with adherence of $80 \%$ or more achieved BP control $(<140 / 90 \mathrm{~mm} \mathrm{Hg}$ or $<130 / 85 \mathrm{~mm} \mathrm{Hg}$ with diabetes) compared with $34 \%$ of patients with adherence of $50 \%-79 \%$ and $33 \%$ of patients 
with adherence lower than $50 \% .{ }^{78} \mathrm{~A}$ logistic regression model demonstrated that patients in the highest adherence group had a 45\% greater likelihood of achieving BP control compared with patients in the lowest adherence group after adjustment for age, gender, and comorbidities $(P=0.026)$.

Increased adherence to antihypertensive medications may also decrease the risk of pressure-related cardiovascular complications. In a retrospective database review of 82,320 patients with newly treated hypertension and no evidence of CVD, a medication possession ratio adherence of $80 \%$ or more was associated with decreased risk of developing chronic heart failure by $11 \%$ after 1 year of follow-up compared with adherence less than $80 \%(P<0.05) .{ }^{85}$ The calculated risk was adjusted for age, gender, social assistance, diabetes, dyslipidemia, presence of respiratory disease, higher chronic disease score, developing a cardiovascular condition during follow-up, and use of antidepressants or anxiolytic agents. In another retrospective analysis of the database involving 83,267 patients with newly treated hypertension and no evidence of CVD who were each matched by age and duration of follow-up to up to 15 control patients, a medication possession ratio adherence of $80 \%$ or more associated with decreased risk of developing cerebrovascular disease by $22 \%$ after 1 year of follow-up compared with adherence less than $80 \%(P<0.05) .{ }^{86}$ The calculated risk was adjusted for cardiovascular risk factors such as adherence to diabetes or dyslipidemia medication, occurrence of a cardiovascular event during antihypertensive therapy, and hypertension severity (assessed by number of antihypertensive agents).

Although further study is needed, the evidence suggests that an antihypertensive medication adherence of $80 \%$ or more appears to improve BP control and decrease the risk of developing some of the complications of hypertension.

\section{Central aortic versus brachial BP}

DBP and mean BP are relatively constant across the central (aortic and carotid) and peripheral (brachial) arterial vasculature. However, because of the phenomena termed pressure wave amplification, brachial SBP and pulse pressure (PP) is higher than the central SBP and PP. The amplification of the central SBP and PP - typically between 10 and $14 \mathrm{~mm} \mathrm{Hg}$ - is a consequence of the transmission of the forward as well as the reflected pressure waves, ${ }^{87}$ the latter emanating mostly from the small muscular resistance arteries and arterioles; thus, there is greater SBP and PP amplification in persons with significant anatomic remodeling of the resistance arteries and arterioles as well as in older persons who typically have stiff, low compliance arterial vasculature.

It is physiologically plausible to hypothesize that central $\mathrm{BP}$ is more important in determining pressure-related risk for cerebral and myocardial disease than brachial BP since the level of central pressure is more reflective than brachial artery pressure of the pressure load these organs face. There are several lines of data that support this hypothesis. In the Strong Heart Study, noninvasively determined central PP was more related to carotid-intima-media thickness and plaque score as well as better predicting 5-year incident CVD than brachial artery $\mathrm{PP}^{88}$ Central pressure is also more closely linked to vascular hypertrophy, left ventricular mass, and the magnitude of carotid atherosclerosis than brachial artery pressure. ${ }^{88-90}$ There are several commercially available devices that allow for estimation of central pressure in clinical settings.

Antihypertensive drugs do not all lower peripheral and central pressures to the same degree. This may also explain, at least in part, why drugs that lower brachial BP by nearly identical amounts lower CVD risk differentially. Beta blockers cause less reduction in central aortic SBP relative to the reduction in brachial SBP in comparison to ACE inhibitors, ARBs, and calcium antagonists. ${ }^{91-93}$ Nevertheless, beta blockers represent a heterogenous drug class and their effects on central pressures may vary as well. Accordingly, atenolol actually increased central PP in comparison with both nebivolol, a newer nitric oxide releasing beta blocker, and placebo in patients with isolated systolic hypertension. ${ }^{94}$ The utilization of noninvasive estimates of central arterial pressures represents an exciting paradigm shift that may ultimately alter the approach to the selection of antihypertensive agents and thus lead to greater CVD risk protection. The results of rigorous, prospective, randomized controlled trials will be required to validate this intriguing hypothesis.

\section{Conclusion}

The number of daily antihypertensive doses affects clinical outcomes both directly, through physiologic mechanisms, and indirectly, by influencing patients' abilities to remain adherent to their medication regimen. Antihypertensive medications should provide 24-hour control while maintaining or restoring a normal circadian BP rhythm. Patients need to understand the importance of taking their medication according to the prescribed regimen.

Once-daily antihypertensive dosing provides favorable 24-hour BP control compared with multiple daily doses. 
Longer-acting agents may produce more gradual decreases in $\mathrm{BP}$ at the onset of action and may produce a lower incidence of adverse events related to drug action than shorter-acting agents. Longer-acting agents may also provide more uniform 24-hour BP control, providing lower early morning BP rises, which may decrease the associated risk for cardiovascular events.

Once-daily antihypertensive dosing has been shown to have the highest adherence rate compared with multipledaily dosing. Increasing the adherence rate to $80 \%$ or more increases the likelihood of achieving BP control and reduces the risk for cardiovascular and cerebrovascular events related to disease progression.

\section{Acknowledgment}

I (JMF) thank Tamalette Loh, PhD, ProEd Communications, Inc $^{\circledR}$, for her medical editorial assistance, for which funding was provided by GlaxoSmithKline, Research Triangle Park, North Carolina.

\section{Disclosure}

I (JMF) have received research support from the National Institutes of Health, Covance, Cardiodynamics Int Corp, Daiichi Sankyo, Sanofi Aventis, Mannkind, and Novartis. In addition, I have served as a consultant or steering committee member for the National Institutes of Health, Cardiodynamics Int Corp, Daiichi Sankyo, Novartis, and GlaxoSmithKline, and have also participated in the speaker's bureau program for Daiichi Sankyo, Novartis, and Pfizer.

\section{References}

1. Chobanian AV, Bakris GL, Black HR, et al. Seventh report of the Joint National Committee on Prevention, Detection, Evaluation, and Treatment of High Blood Pressure. Hypertension. 2003;42(6):1206-1252.

2. Flack JM, Sica DA, Bakris G, et al. Management of high blood pressure in Blacks: an update of the International Society on Hypertension in Blacks consensus statement. Hypertension. 2010;56(5):780-800.

3. Zannad F. Practical relevance of the 24-hour trough: peak ratio of antihypertensive drugs. J Hypertens Suppl. 1995;13(2):S109-S112.

4. Meredith PA, Elliott HL. FDA guidelines on trough: peak ratios in the evaluation of antihypertensive agents. J Cardiovasc Pharmacol. 1994; 23 Suppl 5:S26-S30.

5. Osterberg L, Blaschke T. Adherence to medication. $N$ Engl J Med. 2005;353(5):487-497.

6. Elliott HL. Trough: peak ratio and twenty-four-hour blood pressure control. J Hypertens Suppl. 1994;12(5):S29-S33.

7. Mounier-Vehier C, Bernaud C, Carre A, Lequeuche B, Hotton JM, Charpentier JC. Compliance and antihypertensive efficacy of amlodipine compared with nifedipine slow-release. Am J Hypertens. 1998; 11(4 Pt 1):478-486.

8. Meredith PA. New FDA guidelines on the treatment of hypertension: comparison of different therapeutic classes according to trough/ peak blood pressure responses. Arch Mal Coeur Vaiss. 1994;87(11): 1423-1429.
9. Chi VX, Chau NP. Antihypertensive effect of drugs: statistical distribution of the trough-to-peak ratio. Biometrics. 1996;52(1):286-290.

10. Soucek M, Rihacek I, Frana P. A comparison of the trough-to-peak ratio of cardio-selective beta-blockers in patients with newly diagnosed hypertension. Blood Press Monit. 2006;11(6):337-342.

11. Meredith PA. ACE inhibition and $\mathrm{AT}_{1}$ receptor blockers: efficacy and duration in hypertension. Heart. 2000;84(Suppl 1):i39-i41; discussion i50.

12. Zanchetti A. Trough: peak ratio of the blood pressure response to dihydropyridine calcium antagonists. J Hypertens Suppl. 1994;12(8): S97-S106.

13. Patel PV, Wong JL, Arora R. The morning blood pressure surge: therapeutic implications. J Clin Hypertens (Greenwich). 2008;10(2): 140-145.

14. Amici A, Cicconetti P, Sagrafoli C, et al. Exaggerated morning blood pressure surge and cardiovascular events. A 5-year longitudinal study in normotensive and well-controlled hypertensive elderly. Arch Gerontol Geriatr. 2009;49(2):e105-e109.

15. Gosse P, Neutel JM, Schumacher H, Lacourciere Y, Williams B, Davidai G. The effect of telmisartan and ramipril on early morning blood pressure surge: a pooled analysis of two randomized clinical trials. Blood Press Monit. 2007;12(3):141-147.

16. Lacourciere Y, Neutel JM, Davidai G, Koval S. A multicenter, 14-week study of telmisartan and ramipril in patients with mild-to-moderate hypertension using ambulatory blood pressure monitoring. $\mathrm{Am} \mathrm{J}$ Hypertens. 2006;19(1):104-112.

17. Williams B, Gosse P, Lowe L, Harper R. The prospective, randomized investigation of the safety and efficacy of telmisartan versus ramipril using ambulatory blood pressure monitoring (PRISMA I). J Hypertens. 2006;24(1):193-200.

18. Hermida RC, Ayala DE, Mojon A, Alonso I, Fernandez JR. Reduction of morning blood pressure surge after treatment with nifedipine GITS at bedtime, but not upon awakening, in essential hypertension. Blood Press Monit. 2009;14(4):152-159.

19. Mancia G, Parati G, Castiglioni P, et al. Daily life blood pressure changes are steeper in hypertensive than in normotensive subjects. Hypertension. 2003;42(3):277-282.

20. Bonaduce D, Canonico V, Petretta M, et al. Twenty-four-hour blood pressure monitoring during treatment with extended-release felodipine versus slow-release nifedipine in elderly patients with mild to moderate hypertension: a randomized, double-blind, cross-over study. Eur J Clin Pharmacol. 1997;53(2):95-100.

21. Zannad F, Matzinger A, Larche J. Trough/peak ratios of once daily angiotensin converting enzyme inhibitors and calcium antagonists. Am J Hypertens. 1996;9(7):633-643.

22. Wing LM. Trough: peak ratio of the blood pressure response to betablockers. J Hypertens Suppl. 1994;12(8):S85-S90.

23. Sever PS, Dahlof B, Poulter NR, et al. Rationale, design, methods and baseline demography of participants of the Anglo-Scandinavian Cardiac Outcomes Trial. ASCOT investigators. J Hypertens. 2001; 19(6):1139-1147.

24. Rothwell PM, Howard SC, Dolan E, et al. Effects of beta blockers and calcium-channel blockers on within-individual variability in blood pressure and risk of stroke. Lancet Neurol. 2010;9(5):469-480.

25. Aalbers J. Reduced blood pressure variability in ASCOT-BPLA trial favours use of amlodipine/perindopril combination to reduce stroke risk. Cardiovasc J Afr. 2010;21(2):115.

26. Goyal D, Chong AY, Watson RL, Prasad N, Watson RD. Assessment of single versus twice daily dosing of ramipril by ambulatory blood pressure monitoring in patients similar to those included in the HOPE study. J Hum Hypertens. 2007;21(7):525-530.

27. Routledge F, McFetridge-Durdle J. Nondipping blood pressure patterns among individuals with essential hypertension: a review of the literature. Eur J Cardiovasc Nurs. 2007;6(1):9-26.

28. White WB. Importance of blood pressure control over a 24-hour period. J Manag Care Pharm. 2007;13(8 Suppl B):S34-S39. 
29. De la Sierra A, Redon J, Banegas JR, et al. Prevalence and factors associated with circadian blood pressure patterns in hypertensive patients. Hypertension. 2009;53(3):466-472.

30. Kario K, Shimada K. Differential effects of amlodipine on ambulatory blood pressure in elderly hypertensive patients with different nocturnal reductions in blood pressure. Am J Hypertens. 1997;10(3): 261-268.

31. White WB, Mehrotra DV, Black HR, Fakouhi TD. Effects of controlled-onset extended-release verapamil on nocturnal blood pressure (dippers versus nondippers). COER-Verapamil Study Group. Am J Cardiol. 1997;80(4):469-474.

32. Hermida RC, Calvo C, Ayala DE, et al. Administration time-dependent effects of valsartan on ambulatory blood pressure in hypertensive subjects. Hypertension. 2003;42(3):283-290.

33. Svensson P, de Faire U, Sleight P, Yusuf S, Ostergren J. Comparative effects of ramipril on ambulatory and office blood pressures: a HOPE substudy. Hypertension. 2001;38(6):E28-E32.

34. Yusuf S, Sleight P, Pogue J, Bosch J, Davies R, Dagenais G. Effects of an angiotensin-converting-enzyme inhibitor, ramipril, on cardiovascular events in high-risk patients. The Heart Outcomes Prevention Evaluation Study Investigators. N Engl J Med. 2000;342(3):145-153.

35. Hermida RC, Ayala DE, Mojon A, Fernandez JR. Influence of circadian time of hypertension treatment on cardiovascular risk: results of the MAPEC study. Chronobiol Int. 2010;27(8):1629-1651.

36. Coca A, Calvo C, Sobrino J, et al. Once-daily fixed-combination irbesartan $300 \mathrm{mg}$ /hydrochlorothiazide $25 \mathrm{mg}$ and circadian blood pressure profile in patients with essential hypertension. Clin Ther. 2003; 25(11):2849-2864.

37. Sever P. Candesartan cilexetil: a new, long-acting, effective angiotensin II type 1 receptor blocker. J Hum Hypertens. 1997;11(Suppl 2): S91-S95.

38. McInnes GT. Angiotensin II antagonism in clinical practice: experience with valsartan. J Cardiovasc Pharmacol. 1999;33(Suppl 1):S29-S32; discussion S41-S43

39. Anderson OK, Neldam S. The antihypertensive effect and tolerability of candesartan cilexetil, a new generation angiotensin II antagonist, in comparison with losartan. Blood Press. 1998;7(1):53-59.

40. Smith DH, Matzek KM, Kempthorne-Rawson J. Dose response and safety of telmisartan in patients with mild to moderate hypertension. Pharmacol. 2000;40(12 Pt 1):1380-1390.

41. Accupril ${ }^{\circledR}$ (quinapril hydrochloride tablets) [prescribing information]. New York, NY: Parke-Davis, Division of Pfizer Inc; 2009. Available from: http://dailymed.nlm.nih.gov/dailymed/drugInfo.cfm?id=12730. Accessed November 30, 2009.

42. Capoten $^{\circledR}$ (captopril tablets) [prescribing information]. Spring Valley, NY: Par Pharmaceutical Companies, Inc; 2005. Available from: http:// dailymed.nlm.nih.gov/dailymed/drugInfo.cfm?id=4492. Accessed November 30, 2009.

43. Aceon $^{\circledR}$ (perindopril erbumine tablets) [prescribing information]. Marietta, GA: Solvay Pharmaceuticals, Inc; 2005. Available from: http://dailymed.nlm.nih.gov/dailymed/drugInfo.cfm?id=9343. Accessed November 30, 2009.

44. Lotensin ${ }^{\circledR}$ (benazepril hydrochloride tablets) [prescribing information]. East Hanover, NJ: Novartis Pharmaceuticals Corp; 2009. Available from: http://dailymed.nlm.nih.gov/dailymed/drugInfo.cfm?id=12230. Accessed November 30, 2009.

45. Plendil ${ }^{\circledR}$ (felodipine tablets) extended-release [prescribing information]. Wilmington, DE: AstraZeneca, LP; 2007. Available from: http:// dailymed.nlm.nih.gov/dailymed/drugInfo.cfm?id=11574. Accessed November 30, 2009.

46. DynaCirc $\mathrm{CR}^{\circledR}$ (isradipine tablets), extended release [prescribing information]. Liberty Corner, NJ: Reliant Pharmaceuticals, Inc; 2007. Available from: http://dailymed.nlm.nih.gov/dailymed/drugInfo. $\mathrm{cfm}$ ?id=4147. Accessed November 30, 2009.

47. Verdecchia P, Calvo C, Mockel V, Keeling L, Satlin A. Safety and efficacy of the oral direct renin inhibitor aliskiren in elderly patients with hypertension. Blood Press. 2007;16(6):381-391.
48. Mallion JM, Asmar R, Boutelant S, Guez D. Twenty-four hour antihypertensive efficacy of indapamide, $1.5-\mathrm{mg}$ sustained release: results of two randomized double-blind controlled studies. J Cardiovasc Pharmacol. 1998;32(4):673-678.

49. Guez D, Mallion JM, Degaute JP, et al. Treatment of hypertension with indapamide $1.5 \mathrm{mg}$ sustained-release form: synthesis of results. Arch Mal Coeur Vaiss. 1996;89(Spec No 4):17-25.

50. Floras JS, Jones JV, Hassan MO, Sleight P. Ambulatory blood pressure during once-daily randomised double-blind administration of atenolol, metoprolol, pindolol, and slow-release propranolol. $\mathrm{Br}$ Med J (Clin Res Ed). 1982;285(6352):1387-1392.

51. Neutel JM, Schnaper H, Cheung DG, Graettinger WF, Weber MA. Antihypertensive effects of beta-blockers administered once daily: 24-hour measurements. Am Heart J. 1990;120(1):166-171.

52. Stoschitzky K, Stoschitzky G, Brussee H, Bonelli C, Dobnig H. Comparing beta-blocking effects of bisoprolol, carvedilol and nebivolol. Cardiology. 2006;106(4):199-206.

53. Weber MA, Bakris GL, Tarka EA, Iyengar M, Fleck R, Sica DA. Efficacy of a once-daily formulation of carvedilol for the treatment of hypertension. J Clin Hypertens (Greenwich). 2006;8(12): $840-849$.

54. Kuroedov A, Cosentino F, Luscher TF. Pharmacological mechanisms of clinically favorable properties of a selective beta1-adrenoceptor antagonist, nebivolol. Cardiovasc Drug Rev. 2004;22(3):155-168.

55. Coca A, Sobrino J, Soler J, et al. Trough-to-peak ratio, smoothness index, and circadian blood pressure profile after treatment with once-daily fixed combination of losartan 100 and hydrochlorothiazide 25 in essential hypertension. J Cardiovasc Pharmacol. 2002;39(6):824-833.

56. Kuschnir E, Bendersky M, Resk J, et al. Effects of the combination of low-dose nifedipine GITS $20 \mathrm{mg}$ and losartan $50 \mathrm{mg}$ in patients with mild to moderate hypertension. J Cardiovasc Pharmacol. 2004;43(2): 300-305.

57. Mancia G, Omboni S, Parati G. Twenty-four hour ambulatory blood pressure in the International Nifedipine GITS Study Intervention as a Goal in Hypertension Treatment (INSIGHT). J Hypertens. 2002;20(3): 545-553.

58. Palatini P, Malacco E, Di SS, et al. Trough: peak ratio and smoothness index in the evaluation of 24-h blood pressure control in hypertension: a comparative study between valsartan/hydrochlorothiazide combination and amlodipine. Eur J Clin Pharmacol. 2002;57(11):765-770.

59. Maciejewski S, Mohiuddin SM, Packard KA, et al. Randomized, double-blind, crossover comparison of amlodipine and valsartan in African-Americans with hypertension using 24-hour ambulatory blood pressure monitoring. Pharmacotherapy. 2006;26(7):889-895.

60. Radauceanu A, Boivin JM, Bernaud C, Fay R, Zannad F. Differential time effect profiles of amlodipine, as compared to valsartan, revealed by ambulatory blood pressure monitoring, self blood pressure measurements and dose omission protocol. Fundam Clin Pharmacol. 2004;18(4): 483-491.

61. Zannad F, Bernaud CM, Fay R. Double-blind, randomized, multicentre comparison of the effects of amlodipine and perindopril on $24 \mathrm{~h}$ therapeutic coverage and beyond in patients with mild to moderate hypertension. J Hypertens. 1999;17(1):137-146.

62. Lacourciere Y, Asmar R. A comparison of the efficacy and duration of action of candesartan cilexetil and losartan as assessed by clinic and ambulatory blood pressure after a missed dose, in truly hypertensive patients: a placebo-controlled, forced titration study. Am J Hypertens. 1999;12(12 Pt 1-2):1181-1187.

63. Ohkubo T, Hozawa A, Yamaguchi J, et al. Prognostic significance of the nocturnal decline in blood pressure in individuals with and without high 24-h blood pressure: the Ohasama study. J Hypertens. 2002;20(11): 2183-2189.

64. White WB. Ambulatory blood pressure monitoring: dippers compared with non-dippers. Blood Press Monit. 2000;5(Supp1 1):S17-S23.

65. Dolan E, Stanton A, Thijs L, et al. Superiority of ambulatory over clinic blood pressure measurement in predicting mortality: the Dublin outcome study. Hypertension. 2005;46(1):156-161. 
66. Palatini P, Racioppa A, Raule G, Zaninotto M, Penzo M, Pessina AC. Effect of timing of administration on the plasma ACE inhibitory activity and the antihypertensive effect of quinapril. Clin Pharmacol Ther. 1992;52:378-383

67. Hermida RC, Ayala DE, Fernández JR, Calvo C. Comparison of the efficacy of morning versus evening administration of telmisartan in essential hypertension. Hypertension. 2007;50(4):715-722.

68. Portaluppi F, Vergnani L, Manfredini R, degli Uberti EC, Fersini C. Time-dependent effect of isradipine on the nocturnal hypertension in chronic renal failure. Am J Hypertens. 1995;8(7):719-726.

69. Kario K, Shimada K, Pickering TG. Clinical implication of morning blood pressure surge in hypertension. J Cardiovasc Pharmacol. 2003; 42(Suppl 1):S87-S91.

70. Staessen JA, Thijs L, Fagard R, et al. Predicting cardiovascular risk using conventional vs ambulatory blood pressure in older patients with systolic hypertension. Systolic Hypertension in Europe Trial Investigators. JAMA. 1999;282(6):539-546.

71. Ohkubo T, Metoki H, Imai Y. Prognostic significance of morning surge in blood pressure: which definition, which outcome? Blood Press Monit. 2008;13(3):161-162.

72. Parati G, Faini A, Valentini M. Blood pressure variability: its measurement and significance in hypertension. Curr Hypertens Rep. 2006;8(3): 199-204.

73. Tatasciore A, Renda G, Zimarino M, et al. Awake systolic blood pressure variability correlates with target-organ damage in hypertensive subjects. Hypertension. 2007;50(2):325-332.

74. Parati G, Pomidossi G, Albini F, Malaspina D, Mancia G. Relationship of 24-hour blood pressure mean and variability to severity of targetorgan damage in hypertension. J Hypertens. 1987;5(1):93-98.

75. Frattola A, Parati G, Cuspidi C, Albini F, Mancia G. Prognostic value of 24-hour blood pressure variability. J Hypertens. 1993;11(10): 1133-1137.

76. Cramer JA, Benedict A, Muszbek N, Keskinaslan A, Khan ZM. The significance of compliance and persistence in the treatment of diabetes, hypertension and dyslipidaemia: a review. Int J Clin Pract. 2008; 62(1):76-87.

77. Schroeder K, Fahey T, Ebrahim S. How can we improve adherence to blood pressure-lowering medication in ambulatory care? Systematic review of randomized controlled trials. Arch Intern Med. 2004;164(7): 722-732.

78. Bramley TJ, Gerbino PP, Nightengale BS, Frech-Tamas F. Relationship of blood pressure control to adherence with antihypertensive monotherapy in 13 managed care organizations. J Manag Care Pharm. 2006;12(3):239-245

79. Karve S, Cleves MA, Helm M, Hudson TJ, West DS, Martin BC. Good and poor adherence: optimal cut-point for adherence measures using administrative claims data. Curr Med Res Opin. 2009;25(9): 2303-2310.

80. Hansen RA, Kim MM, Song L, Tu W, Wu J, Murray MD. Comparison of methods to assess medication adherence and classify nonadherence. Ann Pharmacother. 2009;43(3):413-422.
81. Iskedjian M, Einarson TR, MacKeigan LD, et al. Relationship between daily dose frequency and adherence to antihypertensive pharmacotherapy: evidence from a meta-analysis. Clin Ther. 2002;24(2):302-316.

82. Claxton AJ, Cramer J, Pierce C. A systematic review of the associations between dose regimens and medication compliance. Clin Ther. 2001;23(8): 1296-1310.

83. Andrejak M, Genes N, Vaur L, Poncelet P, Clerson P, Carre A. Electronic pill-boxes in the evaluation of antihypertensive treatment compliance: comparison of once daily versus twice daily regimen. $\mathrm{Am} \mathrm{J}$ Hypertens. 2000;13(2):184-190.

84. Leenen FH, Wilson TW, Bolli P, et al. Patterns of compliance with once versus twice daily antihypertensive drug therapy in primary care: a randomized clinical trial using electronic monitoring. Can J Cardiol. 1997;13(10):914-920.

85. Perreault S, Dragomir A, White M, Lalonde L, Blais L, Berard A. Better adherence to antihypertensive agents and risk reduction of chronic heart failure. J Intern Med. 2009;266(2):207-218.

86. Kettani FZ, Dragomir A, Cote R, et al. Impact of a better adherence to antihypertensive agents on cerebrovascular disease for primary prevention. Stroke. 2009;40(1):213-220.

87. Safar ME, Jankowski P. Central blood pressure and hypertension: role in cardiovascular risk assessment. Clin Sci. 2009;116:273-282.

88. Roman MJ, Devereux RB, Kizer JR, et al. Central pressure more strongly relates to vascular disease and outcome than does brachial pressure: the Strong Hearth Study. Hypertension. 2007;50:197-203.

89. Roman MJ, Okin PM, Kizer JR, Lee ET, Howard BV, Devereux RB. Relations of central and brachial blood pressure to left ventricular hypertrophy and geometry: the Strong Heart Study. J Hypertens. 2010;28(2):384-388.

90. Boutouyrie P, Bussy C, Lacolley P, Girerd X, Laloux B, Laurent S. Association between local pulse pressure, mean blood pressure, and large-artery remodeling. Circulation. 1999;100(13):1387-1393.

91. Morgan T, Lauri J, Bertram D, Anderson A. Effect of different antihypertensive drug classes on central aortic pressure. Am J Hypertens. 2004; $17: 118-123$

92. Hirata K, Vlachopoulos C, Adji A, O’Rourke MF. Benefits from angiotensin-converting enzyme inhibitor "beyond blood pressure lowering": beyond blood pressure or beyond the breachial artery? J Hypertens. 2005;23:551-556.

93. Dhakam Z, McEniery CM, Yasmin, Cockcroft JR, Brown MJ, Wilkinson IB. Atenolol and eprosartan: differential effects on central blood pressure and aortic pulse wave velocity. Am J Hypertens. 2006;19: 214-219.

94. Dhakam Z, Yasmin, McEniery CM, Burton T, Brown MJ, Wilkinson IB. A comparison of atenolol and nebivolol in isolated systolic hypertension. J Hypertens. 2008;26(2):351-356
Vascular Health and Risk Management

\section{Publish your work in this journal}

Vascular Health and Risk Management is an international, peerreviewed journal of therapeutics and risk management, focusing on concise rapid reporting of clinical studies on the processes involved in the maintenance of vascular health; the monitoring, prevention and treatment of vascular disease and its sequelae; and the involvement of

\section{Dovepress}

metabolic disorders, particularly diabetes. This journal is indexed on PubMed Central and MedLine. The manuscript management system is completely online and includes a very quick and fair peer-review system, which is all easy to use. Visit http://www.dovepress.com/ testimonials.php to read real quotes from published authors 